Volume 12 | Issue 1

February 2021

\title{
Our People, Our Health: Envisioning Better Primary Healthcare in Manitoba First Nation Communities
}

Grace Kyoon-Achan

University of Manitoba, Canada, Grace.KyoonAchan@umanitoba.ca

Wanda Phillips-Beck

First Nations Health and Social Secretariat of Manitoba, Canada, wphillips-beck@fnhssm.com

Kathi Avery Kinew

First Nations Health and Social Secretariat of Manitoba, Canada, kathikinew@gmail.com

Josée G. Lavoie

University of Manitoba, Canada, Josee.Lavoie@umanitoba.ca

Stephanie Sinclair

First Nations Health and Social Secretariat of Manitoba, Canada, ssinclair@fnhssm.com

Alan Katz

University of Manitoba,Canada,Alan_Katz@cpe.umanitoba.ca

Recommended Citation

Kyoon-Achan, G., Phillips-Beck, W., Kinew, K. A., Lavoie, J. G., Sinclair, S., \& Katz, A. (2021). Our people, our health: Envisioning better primary healthcare in Manitoba First Nation communities. The International Indigenous Policy Journal, 12(1). doi: https://doi.org/10.18584/iipj.2021.12.1.13561 


\title{
Our People, Our Health: Envisioning Better Primary Healthcare in Manitoba First Nation Communities
}

\begin{abstract}
Recognizing the right to self-determination of Indigenous Peoples is essential to improving the state of communitybased primary healthcare (CBPHC) of First Nations in Canada. Understanding communities' priorities and local health agendas is critical for primary healthcare transformation. We used a community-based participatory research approach to engage key partners: Nanaandawewiwgamig, the First Nations Health and Social Secretariat of Manitoba, and eight First Nation communities. Community-based research assistants conducted 183 in-depth interviews in their respective First Nations. Key themes that emerged from these interviews include primary prevention focused on health and social determinants; an integrated healthcare system providing access to both Western medicine and First Nations traditional health knowledge; infrastructure improvement; youth engagement; healthcare leadership; investing in community-based human resources; and promoting culturally respectful, responsive, and geographically sensitive and outcomes-oriented care. Policy approaches could implement some local priorities with direct impact on healthcare, while other social determinants could create indirect, albeit critical, conditions for health and healthcare changes over time.
\end{abstract}

\section{Keywords}

First Nations, community-based primary healthcare, transformation, self-determination, health

\section{Acknowledgments}

We acknowledge the 8 Manitoba First Nation communities who participated in this study, especially the 8 local research assistants who conducted all interviews and maintained a critical link to each community throughout the duration of the study.

\section{Creative Commons License} (c) (1) $\$ 9$

This work is licensed under a Creative Commons Attribution-Noncommercial-No Derivative Works 4.0 License. 


\section{Our People, Our Health: Envisioning Better Primary Healthcare in Manitoba First Nation Communities}

To Indigenous Peoples worldwide, collective and individual self-determination is an inherent right afforded by the Creator. This right, recognized in Canadian law and by the United Nations (Constitution Act, 1867, 1982; Royal Commission on Aboriginal Peoples, 1996; United Nations, 2008), frees Indigenous Peoples in Canada, including First Nations, from the shackles of colonization and the oppressive colonial tendencies of settler governments. This freedom can translate into safe and healthy communities, self-determination, empowerment, and the building of structures consistent with cultural values (Auger et al., 2016; Garces-Ozanne et al., 2016). However, decolonizing for self-determination is a process. Healthcare is at the heart of self-determination because health enables individuals and families to create healthy communities, structures, and systems to govern themselves. Healthy communities in turn secure a healthy future for succeeding generations. The Assembly of First Nations' 2012 Vision Statement posits that First Nations are seeking to smash the status quo in dismantling conditions that hitherto have disempowered, disadvantaged, and harmed First Nation peoples and communities (Assembly of First Nations, 2012). The report suggests that one way to accomplish this decolonization is to affirm First Nation control over First Nation interests, and essentially to transform any current services that are inefficient or inadequate in securing the health and wellbeing of the people.

The current situation is that First Nation communities continue to make do with services that the federal government funds and sometimes provides directly to First Nations; for example, paying nurses who work at federal nursing stations rather than funding communities to hire nurses. These services are supposed to complement those the provincial government provides to First Nation peoples and communities who are residents of the province, as outlined in the Canada Health Act (1984). Ironically, provincial governments and First Nations continue to argue that the federal government holds a primary responsibility for the provision of community-based health services to First Nations. This jurisdictional debate has existed for decades (Booz et al., 1969; Jordan’s Principle Working Group, 2015). However, regardless of jurisdiction, gaps have been documented (Jordan's Principle Working Group, 2015; Lavoie et al., 2008) and the responsiveness of these services have been called into question (Davy et al., 2016; Health Council of Canada, 2012; National Inquiry into Murdered and Missing Indigenous Women and Girls, 2019; Truth and Reconciliation Council of Canada [TRC], 2015).

Some effort has been made to understand key drivers of health in First Nation communities (Bhawra et al., 2017; Davy et al., 2016; Kyoon-Achan, Philips-Beck, et al., 2018; Lavoie, 2013; Smylie \& Firestone, 2015). These drivers include, among others, clarifying healthcare policies, addressing segregated healthcare systems, understanding barriers to care including inadequate medical transportation, increasing access to primary healthcare, addressing social determinants of health, obtaining accurate and relevant statistics for Indigenous populations, and building adequate health structures and infrastructure (Anderson \& Smylie, 2009; Richmond \& Cook, 2016; Richmond \& Ross, 2009). It has also been argued that Canada needs a holistic First Nations healthcare strategy that considers and addresses historical and ongoing structures fueling gross health inequities (Auger et al., 2016; Katz et al., 2017). In previous articles, we argued that transforming community-based primary healthcare (CBPHC) should begin by understanding how that concept can take on an entirely different meaning for First Nation peoples and communities, and it should proceed by developing policies that align with priorities determined by affected communities (Kyoon-Achan et al., 2019; Kyoon-Achan, Phillips-Beck, et al., 2018). In this 
article, we build further on this line of argument to assert that in order to secure long-term positive outcomes in First Nations health, it is imperative to support the implementation of the visions and highest ideals stated by First Nation peoples and communities. First Nations live with those realities in their communities and know what changes could yield the most benefits for CBPHC.

\section{Background}

The Innovation in Community-Based Primary Healthcare Supporting Transformation in the Health of First Nations and rural/remote communities in Manitoba (iPHIT) program of research is a partnership between the University of Manitoba, Nannaandawewigamig, the First Nations Health and Social Secretariat of Manitoba (FNHSSM), and eight Manitoba First Nation communities. The five-year study is funded by the Canadian Institutes of Health Research (CIHR; Study \#297945). Through this program of research, we learned about the unique primary healthcare experiences of First Nation peoples living in communities with various degrees of isolation. Many First Nation communities in Manitoba are remote or isolated. This means that they are long distances away from urban settlements and services. The closest of the eight communities that participated in our study is 2.5 hours away by car from the city of Winnipeg, Manitoba. The farthest is isolated, meaning that it has no road networks, is fly-in only and to get there requires two flights of about 3.5 hours combined.

It is well known that rural and remote communities face unique access and equity challenges when it comes to delivering healthcare that includes a lack of adequate resources, inability to retain healthcare professionals, almost non-existent access to emergency care, and lack of access to preventive care (Fisher-Owens et al., 2016; Oosterveer \& Young, 2015). Power dynamics and differential access to services and resources have historically defined relations between First Nations and mainstream society, resulting in First Nation communities facing health challenges and gross underservice (Horrill et al., 2018; Lux, 2010). Northern isolated and semi-isolated communities in Manitoba have federally funded nursing stations that provide basic first point of contact care, while communities with road access have health centres that provide basic public health services, and residents can presumably access more specialize healthcare in urban centres.

Long-term and continuing care, such as for Elders and others needing palliative care, is offered outside of the community unless the community has a personal care home. Many do not, so Elders who need care end up having to leave their communities (Standing Committee on Indigenous and Northern Affairs, 2018). This is a difficult experience for many Elders (Hampton et al., 2010). Outsiders (usually agency nurses) are typically hired to work in rural and remote Indigenous communities due to a lack of investment in the on-reserve workforce (Wakerman et al., 2019). There is also high turnover among these workers because they may be comparatively under-remunerated and due to the sheer remoteness of the locations. This has significant effects on the quality of care delivered (Minore et al., 2005; Wakerman et al., 2019). It can also be said that limited services, while partially a function of remoteness, isolation, and small populations, is also largely the result of discriminatory policies and outright racism (Bourassa, 2018). Additionally, First Nation communities find themselves entangled in jurisdictional quagmires that often leave the communities underserved when the federal and provincial jurisdictions are not able to clearly define and outline their responsibilities. This creates a paralyzing effect for First Nations that need to access services (Bourassa, 2018; Jordan's Principle Working Group, 2015; Kyoon- 
Achan et al., 2019). These factors taken together result in large health disparities (Benchimol et al., 2018; Frohlich et al., 2006).

Against this background and considering that the health of First Nation peoples continues to show worrying trends, we asked participants to envision and share what CBPHC would look like if they could design their own healthcare system to address current challenges or optimize successes. This article shares the responses of eight Manitoba First Nation communities. Following the aforementioned contextual factors affecting the health of First Nation communities in Manitoba and discussion of the concerns that informed this study, we briefly describe the method of engagement and discuss promising results for a healthcare system that could better serve First Nations in community-based contexts.

\section{Study Design}

Using a community-based participatory action research framework, all partners collaboratively designed and implemented the study. This method has been shown to support respectful research with Indigenous Peoples (see for example Boffa et al., 2011; Brunger \& Wall, 2016; Flicker et al., 2015). Ethical practice goes beyond merely following the usual recommendations made by institutions; it requires engagement that is meaningful and useful for community partners (Brunger \& Wall, 2016; Canadian Institutes of Health Research, 2010; Kyoon-Achan, Lavoie et al., 2018; Phillips-Beck et al., 2019). First Nation communities and individuals participating in this study provided guidance and feedback at all stages of the study including questionnaire development, data collection, interpretation, analyses, and knowledge translation. We have published a more fulsome description of the methods (see Kyoon-Achan, Lavoie et al., 2018).

\section{Methods}

\section{Partnership Formation}

The First Nations Health and Social Secretariat of Manitoba (FNHSSM) and university-based researchers teamed up with eight Manitoba First Nation communities. These Nations were selected to represent all geographical locations in Manitoba of isolated (no road access), semi-isolated (with seasonal roads), and non-isolated (with road access) communities (Table 1). They also represent four of five First Nation languages in Manitoba: Dakota, Dene, Cree, and Ojibway. These partners had frequent in-person and teleconference meetings throughout the duration of the partnership (PhillipsBeck et al., 2019). Each community was equally represented by a local research assistant (LRA) and health director.

\section{Ethics Approvals}

Ethics approvals were sought and obtained from the University of Manitoba Human Research Ethics Board (UM-REB) and the First Nations Health Information Research Governance Committee (HIRGC) at FNHSSM. The First Nation Chiefs of Manitoba mandated the HIRGC since 1998 to oversee research ethics processes on behalf of Manitoba First Nations. Following both approvals, consent letters in the form of Band Council Resolutions (BCR) were also obtained from respective communities, and consent forms were completed by individual respondents prior to conducting interviews. 
Table 1. Characteristics of Participating Communities

\begin{tabular}{ccccc}
\hline Community & Language & Size & Model of care & Geography \\
\hline Community 1 & Ojibway & Medium & Nursing station & Southern isolated \\
Community 2 & Dakota & Small & Health centre & South non-isolated \\
Community 3 & Cree & Large & Nursing station & North semi-isolated \\
Community 5 & Cree & Medium & Health centre & South non-isolated \\
Community 6 & Ojibway & Medium & Health centre & South non-isolated \\
Community 7 & Cree & Large & Nursing station & Northern non-isolated \\
Community 8 & Dene & Small & Nursing station & Northern isolated
\end{tabular}

Note. North and northern communities are those north of the $53^{\text {rd }}$ parallel in Manitoba, while South and southern communities are located south of this parallel.

\section{Written Agreements}

Written agreements were signed between First Nation communities and researchers in keeping with HIRGC requirements including First Nations Ownership, Control, Access, and Possession ( $\mathrm{OCAP}^{\circledR}$ ) principles (First Nations Information Governance Centre, 2014). OCAP ${ }^{\circledR}$ and other principles are intended to regulate and guide research involving First Nations so that research is conducted respectfully and meaningfully for community partners. It is also imperative that research data becomes a tool to strengthen First Nation inherent rights to self-determination. Therefore, to promote "ownership," "control," and "access," the FNHSSM acted as the "secretariat" for the study with all data management and analysis activities maintained at that location. Participating communities can access the data at any time upon request. To ensure "possession" and use, all data were made available to participating communities in various formats: reports, presentations, conferences, meetings, publications, and factsheets. They were free to utilize this information for healthcare planning, decision making, and policy development during the study and thereafter.

\section{Data Collection}

Purposive sampling targeted male and female community members, Elders, healthcare workers in the community, and health services users. Open-ended interviews adopted a decolonizing approach consistent with Indigenous methods in that they were semi-structured and storied, inviting respondents to engage with the subject matter freely and expansively (Baskin, 2005; Chilisa, 2012; Iseke, 2013). Interviews and post interview data validations were completed between April 2014 and December 2016. In total, 183 interviews were completed with individuals from eight communities. The research team 
recruited and trained eight community-based LRAs to collect data in each community. Each LRA could translate questions and responses into the respective local language or English, as necessary, to accommodate Indigenous language speaking participants. A few respondents made comments in their own languages that were then translated by the LRA into English before transcription.

\section{Data Analysis}

All interviews were sent to a professional transcriber for verbatim transcription. Transcripts were then de-identified by removing any names and interview locations and sent back to communities for their information and for validation. Usually LRAs, health directors, and other individuals chosen by the community vetted the data to ensure accuracy of concepts and to confirm any words or meanings that had been conveyed in local languages had been correctly translated. Participating communities were also involved in the interpretation of data through community and regional workshops that continued into 2018. LRAs continued to be available to review, translate, and explain terms, meanings, and contexts for increased clarity throughout the data analysis. Communities validating and essentially co-interpreting de-identified data to highlight key ideas in their data ensured accuracy and significantly reduced the "researcher effect" on the analysis (Miles \& Huberman, 1994). Two university-based and two FNHSSM-based data analysts collaborated on the data analysis. However, one researcher who liaised between the university, FNHSSM, and all partnering communities (GKA) manually completed preliminary data analysis using an open coding system to identify key ideas and themes, then uploaded the data to NVivo 10 software for further coding. The results summarized below emerged from both the interview data as well as from interpretive discussions during community data validation and interpretation sessions. The quotes have been selected to represent themes emanating from all participating communities.

\section{Results}

The results include 10 key themes that emerged (Table 2), each presented according to its own merit and not in any particular order. There was no indication in the data that any one factor was more important or was preferred over others. Some of the themes could have direct impact on healthcare while others could have indirect impact on healthcare services.

Some differences existed in the data between communities, reflecting unique circumstances such as size, model of care, and geographical location. For example, road-access communities highlighted the need for more vehicles to transport patients, while northern remote communities with nursing stations expressed the need for more nurses, larger health facilities, and community-based rather than transient staff who travel in and out of the communities. However, the focus of this article is to outline common factors that were important to all participating communities. Common factors impacting First Nations healthcare experiences drawn from individual community realities reveal the collective disempowerment of First Nations in the larger healthcare system. However, in order to highlight the specific context, the respondent's community is indicated at the end of quotations. 
Table 2. List of Themes and Potential Impact on CBPHC Services

\begin{tabular}{cc}
\hline Direct impact on healthcare services & Indirect impact on health services \\
\hline Integrated healthcare services & Focus on prevention \\
Larger health facilities & Intersectoral collaboration \\
First Nation control of resources & Empowerment \\
Medical transportation & Youth engagement \\
Permanent community-based staff & Leadership \\
\hline
\end{tabular}

\section{Integrated Healthcare System}

Respondents want the "Western" or modern healthcare system to collaborate with traditional health knowledge in the spirit of cooperation to serve First Nation populations holistically.

I would get two different options. One side would be traditional, one side would be [mainstream] medicine. So it will be both sides. If one person wants to take healing from both of them, they have that option. There's [traditional] medicine men there that can do the quality work as a doctor but are not recognized in health authorities. They don't have that paper saying I'm a doctor but traditionally they have that honor. So there will be options where people can go to. That's a good health system. [Large northern semi-isolated community respondent]

It is believed that an integrated healthcare system could expand options to patients and provide First Nation peoples the freedom to choose.

We do offer the doctor or hospital type of stuff. But what about the traditional part of it? I've seen buildings where they have a specific room for smudging and for anybody who wanted to talk to somebody other than a mental health worker, somebody that would understand exactly where they're coming from. [Southern non-isolated community respondent]

We would need to adopt a program that would be able to provide funds to access these herbs and roots, because I'm sure some of them are located in out of the way places. This is what supports are needed to promote use of traditional medicine. It's educating and it's also funding the access to these traditional medicines. [Southern isolated community respondent]

To enable a meaningfully integrated healthcare system, respondents want funding to support education about and access to traditional healthcare options so people can make educated choices when the need arises. 


\section{Focus on Prevention}

Respondents talked about the need to focus on prevention in First Nation communities as a way to protect and promote health rather than managing illnesses and diseases.

We're so focused on intervention right now, it's really tough to focus on prevention models. If we could front-load our prevention models a lot more, then the better because that means we're doing everything we can to provide tools and skills to address those health issues before they become life threatening. [Southern non-isolated community respondent]

They envisioned robust prevention programs that would begin with community assessments to determine needs.

Well, first of all you would have to do a thorough community assessment. And identifying those needs ... to see what kind of needs we [as a community] have. You build your framework from there and then you designate how to build [based on] that framework and then you build. When you identify that that's the priority in the community. [Northern semi-isolated community respondent]

You definitely have to consult with the grassroots people first before starting anything and ask them and get their input on what they would like to see within a health centre, or the health system ... Yeah, I'd definitely ask the grassroots people first and then work my way up that way. [Southern non-isolated community respondent]

The identification of community needs would then be followed by long-term program planning.

Rural First Nation communities, the emphasis of the care is generally on reactional medicine as opposed to preventative medicine, as opposed to upper stream programming. Time constraints limit us from being able to plan ahead with upper stream programming. [Southern isolated community respondent]

Upstream programming would generate action in key areas respondents identified, including health promotion, community outreaches, education, and workshops in relevant areas. Some specific examples mentioned include dealing with root causes of addictions in the community; educating parents on the impact of videogames on children; health and safety concerns, notably unsafe roads in the communities; and preventing pollution of waters by encouraging garbage cleanup. It was also pointed out that poor living conditions due to poverty, overcrowding, and mold in homes negatively affect health. Respondents want First Nation communities to be made amply aware of these factors.

\section{Intersectoral Collaboration}

Respondents in all communities wanted health and social services operating in the community to be able to work together and share information, as necessary.

[There is a perception that community-based staff] can't legally share information with their clients or with other [programs]. That creates a wall and that creates a barrier... That's what we 
need to address. If we really want to open these doors up to working with one another, we have to get over that confidentiality issue. One way I see us doing that is creating our own constitution as a community, creating our own law basically. An individual should be surrounded by all our support services, not an individual reaching out to our [various] support services. We need to flip that way of thinking around. But because of I'll say, certain laws, we're not allowed to do that. And our people are scared to breach those laws even though we as a community have a value of caring and they know that they can help a person by surrounding them with these different services. That's what's preventing us from really getting out there. [Southern non-isolated community respondent]

Respondents also thought that bringing all services together would encourage collective program assessments in order to understand what is working and what areas may need improvements.

We would have this wonderful nursing station where all the health resources people and their nurses are working together ... all working together and were having meetings and we know what's working and what's not working. [Northern isolated community respondent]

It was further suggested that resources can be pooled together as one way to encourage the various sectors collaborating.

It's up to the people to come together, all combine as one package. With everybody on the train, you got to combine with one another to see how you can make everything better. [Northern non-isolated community respondent]

\section{Larger Healthcare Facilities}

Respondents in larger communities wanted to have access to the same level of coordinated services available in non-First Nations communities. One larger community had described this as a hospital due to the fact that their relative size would warrant such a facility if they were not under federal jurisdiction. Some others called for a "healthcare centre" in their communities.

Our population has grown in the last few years; we have enough people here to have a hospital. This place needs a hospital. I mean we've just got a tiny little nursing station there; you go there and like you go there in the morning, whatever, that place is jammed pack, right until it's time to go home, whatever time they quit working there. [Northern semi-isolated community respondent]

The request for hospitals was associated with having larger facilities to accommodate the healthcare needs of growing population and to reduce overcrowding at the existing nursing stations. Respondents also thought that having a community-based hospital would reduce the current practice where patients leave their families and communities to travel into towns and cities for medical care. Many emphasized that difficulties currently being faced by commuting patients could be avoided especially if Elder patients do not have to leave their communities for care elsewhere. Examples were shared such as not having transportation to attend appointments and nonexistent or inadequate accommodations in towns and cities. 
Respondents also said that having larger facilities will enable all healthcare services to be under the same roof or closer together and perhaps communicate better when needed. Making referrals would also be easier, and patients would possibly be more likely to follow through with their appointments.

We're all scattered. We're not just in one building as health workers. The nursing station is over there, they are here and the [community health representative] are in a different area too.

Sometimes they don't know what's going on. So if we all have one building that would be easier. [Northern semi-isolated community respondent]

A "hospital" in the community, it was also believed, would have more equipment to serve the population such as a dialysis unit, $\mathrm{X}$-ray machines, and other diagnostics.

Well like I said, hospitals, more resources in the community instead of having to go out of the community for resources such as certain X-rays which would be done here if we had the resources. [Northern semi-isolated community respondent]

All communities made requests to have community-based hospitals, as well as improved infrastructure with all equipment, amenities, and staff complement including physicians, dentists, pharmacists, etc.

\section{First Nations Control}

Some respondents said that having First Nations healthcare services under First Nations control and ownership would result in better services for the communities.

The system now is kind of segregated, different entities, and establishing the one entity, First Nations controlled, has ownership, I think would provide better access and more would have a bigger effect on the overall community health of the people. [Northern semi-isolated community respondent]

[Our] own health system, my idea is to pick our own people to run it, to give them the power, to empower them not to depend on the government. We run our own system, we make our own money to run our system, and our people to run healthcare, our nurses or doctors, counsellors, our Elders. They run the show and we are all under one building where everybody will be at. [Northern non-isolated community respondent]

Yes, run by our own people so that way we know what's going on. [Northern isolated community respondent]

Communities said that they would be better able to determine and implement programs that are really needed rather than whatever is dictated by funding and funders. It was suggested, for example, that current nursing and health care aide programs should be tailored and laddered to make it easier for First Nations learners to achieve higher levels. In one respondent's words, First Nations ownership would entail:

Less interference from the [government], like right now really we're simply an agent of the federal government, we administer their programs. We need access to resources which we [First 
Nations ] can control and be accountable for, but control as we see fit and I know that FNIHB [First Nations and Inuit Health Branch] would argue that we have that now, but yeah the programs are still all too narrow and not enough. [For example] there is no traditional food program, there's no traditional land use program, those are all health-related issues helping people with mental health for example through traditional land use, there's no programming like that. There's no money to help people decolonize, there's a therapist that comes in, but do they really know anything colonization and whatever? We need to actually ... create that here. That should be a responsibility of the federal government, because it's through the residential and day schools that all got taken away. [Southern isolated community respondent]

First Nations control was seen as a beginning to decolonization through which communities would be at liberty to design and implement programs to meet the current and future health needs of the people. The respondent implied that CBPHC has been stymied by lack of committed resources by the federal and provincial governments. For example, federal funding to First Nations health has been frozen for two decades due to federal insistence on meeting provincial standards, which may not be realistically attainable at this time. However, one specific area of need that First Nations would prefer to immediately address is establishing personal care homes in the communities. Every participating community expressed a desire for "old folks' homes" for Elders and sick people in the community.

\section{Empowerment}

Respondents recognize:

First Nation communities are behind in our health services compared to what they are given in provincial or off-reserve facilities and our people are struggling but they are trying hard. [Southern, non-isolated community respondent]

They thus imagined communities in which people would be empowered to take responsibility for their own health and have the options to make choices that lead to better health.

I believe it lies with the community members themselves, taking responsibility of their own health, creating more independence for our community members because I do find a lot of them are dependent on our [health] services, which is great, but I would like to see more independence in their health and taking more part. [Southern non-isolated community respondent]

The hard part is implementing the process and the important part is people. So people have to buy in to change, to improve. There's always resistance to change. I think when I look at the community as a whole, the whole community organization, our government structure, I think we're too familiar with the way things have been that we can't think forward. We don't think ahead or visualize how it could be. It looks like a lot of work for people and maybe the motivation, the morale is low. It's keeping people stuck. And not only one person can make those changes. It's got to be people, community who say, "Let's get on board. Let's help one another and support one another and make those changes for our community." It involves people as a whole to make the community better and improve. [Northern isolated community respondent] 
Respondents suggested that with the right supports, First Nation communities can assume increased responsibility for their health by implementing solutions that may be within or outside the current healthcare models currently available in communities.

\section{Youth Engagement}

Respondents advocated collaborations between health services and schools in First Nation communities. They maintained that this partnership could create joint activities to wrap around and strengthen supports for youth and solidify the health and social messaging to keep the young population healthy and living better lives. It was suggested that an investment in youth is an investment in the overall wellbeing of the community. One respondent expressed the sentiment as follows:

I think we [health centre] need to have a better linkage with the school because they have 700 kids at that school ... we could give them more services, we could help because the kids are going to make or break our community. So we need to focus on the kids and on the youth and because they're the ones that are going to take over this health centre one day... If the kids got healthier and more cultural, it would be such a positive thing in all areas. Not just the health like the whole community in general. [Southern non-isolated community respondent]

Respondents said that youth living in First Nation communities need a place to be and activities to engage them.

There is nothing for them to do other than what they do at home. And they have all this technology they're using and they don't go outdoors. We need stuff out here to get these kids involved. [Southern non-isolated community respondent]

Getting children and youth into more activities so that they do not turn to drugs or alcohol at an early age. [Southern non-isolated respondent]

Several more respondents expressed concerns about kids eating unhealthy diets and leading sedentary lives. Some therefore wanted fitness centres in all communities that do not currently have any. Some envisioned that the fitness centre would have activities for all age groups and would be affordable. Others mentioned having playgrounds and parks that are located in safe spots for children to play in.

\section{Medical Transportation}

Respondents envisioned having effective medical transportation. These would include communityowned ambulances for use during emergencies, handicap vans for people with disabilities, and vans to transport people to and from medical appointments within and outside the community. It was said that some lives are lost, and other people miss medical appointments due to lack of transportation.

We'd have our own ambulance. We'd have our own medevac. A quick way to get to our emergency situations. [Southern non-isolated community respondent] 
And the ambulance and the handicap. We need handicap vans because a lot of our people here are going into wheelchairs and have difficulty accessing the hospital [and] clinics, so that's what we would need out here. [Southern non-isolated community respondent]

Respondents agreed that effective medical transportation would increase access to healthcare in general for people living in remote communities and for people who have become disabled due to other chronic health conditions.

\section{Community-Based Healthcare Leadership}

Respondents pointed out the importance of having strong leadership for all healthcare programs in the community.

We have to have a health director that cares for this community, the people, young and old. We have to have a health director to make sure everybody's at work on time and leaves on time, that's what I mean by consistency. We have to have a health director who does not travel and leave this community every Friday and through the weekend. We need someone that stays within our community to oversee everything that is going on in that nursing station. [Southern isolated community respondent]

Respondents want health directors that will be committed to the community, preferably reside in the communities that they work in and ensure that nursing stations, health centres, and all staff work diligently to serve the health needs of the communities. Some respondents also pointed out the need for leadership to maintain "open dialogue" so the community is encouraged to provide feedback on all health programs and suggestions for how those programs can be improved.

It was important for people that leaders and programs in the community work together.

The people that are in charge of things have to work together you know ... share their ideas and share their problems and come up with better solutions. Like the doctor... when she's here maybe she could come to those meetings and the nurse could be there ... and the mental health worker could be there and maybe one person from the Chief and Council could be there, maybe the principal from the school could be there you know, maybe somebody from CFS [Child and Family Services] could be there you know. A close working relationship is good, with all the programs, all the facilities. That is how I would design something, people to work together more closely. [Southern isolated community respondent]

\section{Permanent Community-Based Staff}

Additionally, respondents envisioned having permanent doctors, nurses, and staff who will reside in the communities they work in, and who get to know their patients better.

We have different doctors coming in now and then. We need to have a permanent doctor stationed here in the community, to know the people, their health, to know that person slowly. And the person, the people will know this doctor. I don't even know who my doctor is now. I don't know what his name or her name is. They keep changing these doctors on us as well as 
these nurses. But we need full-time staff in this facility so everybody will know each other. We'll know who the doctor is, we'll know who the nurses are, and the nurses as well and the doctor as well will know us. But if they keep changing them, you know, it's confusing. It's like when you read a book and you got a little way and then you put that book aside and then for two weeks or a month, and you have to start over again to read from the beginning. It's like that and that's what I see here, it's like, you know, we need fulltime staff, nurses and doctors. [Southern isolated community respondent]

Respondents want doctors to know their patients in communities better and for patients get a chance to cultivate relationships with their doctors over time as well. Some also said that having full-time community-based staff will ensure that emergencies in the community will be better dealt with when they arise, and chances of delays or misdiagnosis may be reduced.

\section{Discussion}

The eight Manitoba First Nations who participated in this study have discussed current issues in CBPHC and provided a comprehensive vision of what they believe will make a significant difference in CBPHC. Themes include having integrated healthcare services that provide traditional health options, building larger health facilities, First Nation control of resources so as to determine and fund priority needs, readily available medical transportation, having permanent community-based staff to promote continuity of care, a focus on key prevention programs and activities that support wellbeing and health, encouraging inter-sectoral collaboration and knowledge sharing among programs in the community, empowering youth, as well as strengthening local leadership. It is noteworthy that the recommendations to transform the system made by respondents in this study may not be groundbreaking by themselves, but their collective impact could be. Manitoba First Nations are requesting services that are routinely enjoyed by the majority of Canadians who perhaps could not imagine living without those services. Each theme could have significant effects on health outcomes.

An integrated health system could allow First Nation peoples to choose healthcare options that meet their health needs. Studies have indicated promising practices through successful integration attempts (Drost, 2019; Fijal \& Beagan, 2019; Ho et al., 2006; Murdoch-Flowers et al., 2019). Within this system, access to and application of traditional healing protocols and ceremonies are provided within mainstream health facilities, cultural competency is an integral part of the healthcare environment, and dedicated funding is available to support the practice. Including sacred spaces and incorporating the Sweat Lodge as a traditional healing ceremony into the Alberta Health Services is a case in point, even though much work remains to be done (Drost, 2019). Another example is the inclusion of breathing techniques and traditional spirituality in a Kahnawake School Diabetes Prevention Project, which saw improvements in holistic health and wellbeing (Murdoch-Flowers et al., 2019). These practices do not merely target the body but also extend to support mental, emotional, and spiritual wellbeing. We know that First Nation people utilize traditional medicines and therapeutic practices (Colantonio \& Rivers, 2017; Drost, 2019; Lans, 2016; Royal Commission on Aboriginal Peoples, 1996). Studies also share instances of people combining traditional remedies with mainstream approaches (Cook, 2005; George et al., 2018; Zubek, 1994) and finding them useful for their health and wellbeing. An integrated system would however require specific financial and technical supports for initiatives such as medical transportation to attend traditional healing practices and activities as necessary, remuneration for 
traditional medicine practitioners, and personnel to coordinate between traditional and allopathic medical care. An integrated system would also possibly require enhanced collaboration between traditional medicine people and practitioners of allopathic medicine (Redvers et al., 2019).

Several respondents said they wanted "hospitals" in communities. Upon closer examination, it appears that many respondents envision larger healthcare facilities, better access to physicians, specialists, technicians, nurses, all necessary equipment, and resources for use in the communities. With increasing populations, some First Nation communities have outgrown their current healthcare facilities. Respondents want to replace the understaffed and underfunded nursing stations or health centres with larger and better resourced facilities to accommodate the rising needs in communities. The current reality is that First Nation communities operate models of care that draw heavily on nursing care and occasional physician visits. These models to do not support continuity of or quality of care (Standing Committee on Indigenous and Northern Affairs, 2018). Healthcare tends to fall in the hands of a few available workers, and it will become compromised and fragmented when these workers are overloaded, pressed for time, and poorly equipped, an observable occurrence in First Nation communities. First Nation communities suggest improving CBPHC by providing larger, better equipped healthcare facilities. This could make it easier for First Nation communities to attract and retain the services of healthcare workers, specialists, and physicians where possible. Larger facilities can also make room for better diagnostic equipment. This could improve diagnostics and enhances early disease detection which in turn may reduce death rates (Ball \& Balogh, 2016). First Nation communities have decried the state of diagnostic equipment in their communities. Patients often travel long distances for diagnostic tests that could be conducted at healthcare facilities in the community if they were available. This problem could be eliminated by purchasing new or updating existing equipment and then hiring or training First Nation workers to fill those service positions in the community.

Medical transportation services are a determinant of First Nation health and can significantly hamper or improve access to healthcare for First Nation patients (Davy et al., 2016). It is one of the health benefits that the federal government provides to First Nation communities according to the government's own regulations (Government of Canada, 2018). Decision-making by First Nations concerning medical transportation is limited by policy rules and regulations. For example, provincial requirements state that a physician at receiving institutions must approve medical evacuations. This often delays emergency decision-making depending on whether a physician is available or deems the circumstance to be an emergency, despite not being physically present to make an assessment. Medical transportation is critical nonetheless, as some people living in First Nation communities would otherwise not be able to commute to a nursing station in the community, get to medical appointments in different towns and cities, or be evacuated in a medical emergency to get help in a timely manner. This situation is made worse when there are no publicly funded transportation systems available in communities and many First Nations do not have adequate emergency response services, do not own ambulance services, and often do not having physicians on site in communities to attend to medical emergencies. More so, increasing rates of chronic conditions, such as diabetes-related amputations in First Nation patients (Canadian Diabetes Association, 2016; Pelletier et al., 2012), is creating additional need for accessible transportation for people with disabilities to support access to ongoing care. Additional medical transportation in the form of vehicles, ambulances, and around the clock drivers will significantly improve access to care for First Nations living in remote communities. 
First Nation communities have further highlighted the need to protect succeeding generations by occupying First Nation youth with activities to inspire better choices for their own health and, in so doing, improve the health of entire communities in the long term. Engaging youth in and of itself has been shown to curb social vices and create lasting change (Geldhof et al., 2013; Iwasaki \& Hopper, 2017; Suleiman et al. 2006). First Nations in this study recognize that youth are key allies in creating healthier futures for their communities and want them to be meaningfully engaged. This goal is being achieved in some cases through targeted First Nations youth engagement initiatives, or support such as the establishment of junior Chiefs and Councils to enhance leadership skills, or junior ranger programs available in some First Nation communities to promote land-based skills. These and similar activities are also avenues for health promotion and social awareness initiatives.

It has previously been shown that First Nations control of healthcare services benefits communities and leads to better health outcomes (Lavoie et al., 2010). Positive health outcomes could therefore be amplified with increasing First Nation control over community-based healthcare systems, ensuring, for instance, that health programs are tailored to address specific community needs and priorities. The programs would be culturally relevant and possibly incorporate the languages of the populations that are served for easier and better communication. We already know that healthcare providers who understand the language, culture, and community context of their clients may build more trust which helps in providing quality care (Ventura \& Rueter, 2018). The reverse can create feelings of distrust in patients (Webster, 2018). This problem can be eliminated by adequately supporting First Nation owned and controlled healthcare services predominated by First Nation professionals with broad understanding of the socio-cultural milieu. More so, with greater control over resources, First Nations can and do establish appropriate regulations and evaluation of healthcare services.

\section{Conclusion}

First Nations communities in Manitoba have provided a vision for better CBPHC. Stakeholders including governments, policy makers, health planners, and community-based leadership can develop implementation strategies with and within concerned First Nation communities. Themes from respondents' views should be seen as interconnected in their ability to contribute to better CBPHC. It appears that self-determination is at the apex of respondents' shared vision, and First Nation control of resources is a component, which would allow communities to direct funds to priorities such as larger buildings for nursing stations, for example, or additional infrastructure such as personal care homes and lodges for Elders and others requiring long-term care. First Nations self-determined healthcare could put greater emphasis on prevention programs. Local autonomy on healthcare planning and decisionmaking could also allow for integrated healthcare systems with easier access to traditional options. Local control of medical transportation funding could also create easier and faster access to off-reserve care. In creating conditions and capacities to implement desired healthcare transformations over time, youth would be a key part of healthcare planning and would take the lead in addressing social determinants of health. This proximity to planning and decision-making may inspire youth entries into health professions and contribute to closing the gaps on permanent community-based workers when young people return to their communities to work. In general, however, a clear vision of optimal communitybased primary healthcare in First Nation communities has been articulated, which could help in prioritizing funding and resources to meet needs in priority areas. Ultimately, self-determination in 
CBPHC is the goal, which could be achieved by supporting First Nation communities' paths to improved health for current and future generations.

\section{References}

Anderson, M. J., \& Smylie, J. K. (2009). Health systems performance measurement systems in Canada: How well do they perform in First Nations, Inuit, and Métis contexts? Pimatisiwin, 7(1), 99115. https://pubmed.ncbi.nlm.nih.gov/23450984

Assembly of First Nations. (2012). First Nations plan: Honouring our past, affirming our rights, seizing our future. https://www.afn.ca/uploads/files/cfng/2012-first-nations-plan.pdf

Auger, M., Howell, T., \& Gomes, T. (2016). Moving toward holistic wellness, empowerment and selfdetermination for Indigenous Peoples in Canada: Can traditional Indigenous health care practices increase ownership over health and health care decisions? Canadian Journal of Public Health/Revue canadienne de santé publique, 107(4-5), e393-e398. https://doi.org/10.17269/ cjph. 107.5366

Ball, J. R., \& Balogh, E. (2016). Improving diagnosis in health care: Highlights of a report from the National Academies of Sciences, Engineering, and Medicine. Annals of Internal Medicine, 164(1), 59-61. https://doi.org/10.7326/m15-2256

Baskin, C. (2005). Storytelling circles: Reflections of Aboriginal protocols in research. Canadian Social Work Review, 22(2), 171-187. http://www.jstor.org/stable/41669834

Benchimol, E. I., Kuenzig, M. E., Bernstein, C. N., Nguyen, G. C., Guttmann, A., Jones, J. L., Potter, B. K., Targownik, L. E., Catley, C. A., Nugent, Z. J., Tanyingoh, D., Mojaverian, N., Underwood, F. E., Siddiq, S., Otley, A. R., Bitton, A., Carroll, M. W., deBruyn, J. C., Dummer, T. J., ... Kaplan, G. G. (2018). Rural and urban disparities in the care of Canadian patients with inflammatory bowel disease: A population-based study. Clinical Epidemiology, 10, 1613-1626. https://doi.org/10.2147/clep.S178056

Bhawra, J., Cooke, M. J., Guo, Y., \& Wilk, P. (2017). The association of household food security, household characteristics and school environment with obesity status among off-reserve First Nations and Métis children and youth in Canada: Results from the 2012 Aboriginal Peoples Survey. Health Promotion and Chronic Disease Prevention in Canada: Research, Policy and Practice, 37(3), 77-86. https://doi.org/10.24095/hpcdp.37.3.03

Boffa, J., King, M., McMullin, K., \& Long, R. (2011). A process for the inclusion of Aboriginal People in health research: Lessons from the Determinants of TB Transmission project. Social Science and Medicine, 72(5), 733-738. https://doi.org/10.1016/j.socscimed.2010.10.033

Booz, A., \& Hamilton of Canada, Ltd. (1969). Study of health services for Canadian Indians: Summary report. Department of National Health and Welfare. 
Bourassa, C. (2018). Addressing the duality of access to healthcare for Indigenous communities: Racism and geographical barriers to safe care. Healthcare Papers, 17(3), 6-10. https://doi.org/ 10.12927/hcpap.2018.25507

Brunger, F., \& Wall, D. (2016). "What do they really mean by partnerships?” Questioning the unquestionable good in ethics guidelines promoting community engagement in Indigenous health research. Qualitative Health Research, 26(13), 1862-1877. https://doi.org/10.1177/ $\underline{1049732316649158}$

Canada Health Act (R.S.C., 1985, c. C-6). https://laws-lois.justice.gc.ca/eng/acts/c-6/page-1.html

Canadian Diabetes Association. (2016). Report on diabetes in Manitoba.

Canadian Institutes of Health Research. (2010). CIHR guidelines for health research involving Aboriginal people (2007-2010). http://www.cihr-irsc.gc.ca/e/29134.html

Chilisa, B. (2012). Indigenous research methodologies. Sage Publications.

Colantonio, S., \& Rivers, J. K. (2017). Botanicals with dermatologic properties derived from First Nations healing: Part 1-Trees. Journal of Cutaneous Medicine and Surgery, 21(4), 288-298. https://doi.org/10.1177/1203475417690306

Constitution Act, 1867. 30 \& 31 Victoria, c. 3 (U.K.). https://laws-lois.justice.gc.ca/eng/Const/page$\underline{1 . h t m l}$

Constitution Act, 1982, Schedule B to the Canada Act 1982 (UK), 1982, c 11. https://lawslois.justice.gc.ca/eng/Const/page-15.html\#h-38

Cook, S. J. (2005). Use of traditional Mi'kmaq medicine among patients at a First Nations community health centre. Canadian Journal of Rural Medicine: The Official Journal of the Society of Rural Physicians of Canada, 10(2), 95-99.

Davy, C., Harfield, S., McArthur, A., Munn, Z., \& Brown, A. (2016). Access to primary health care services for Indigenous Peoples: A framework synthesis. International Journal for Equity in Health, 15(1), 163. https://doi.org/10.1186/s12939-016-0450-5

Drost, J. L. (2019). Developing the alliances to expand traditional Indigenous healing practices within Alberta Health Services. Journal of Alternative and Complementary Medicine, 25(S1), S69-S77. https://doi.org/10.1089/acm.2018.0387

Fijal, D., \& Beagan, B. L. (2019). Indigenous perspectives on health: Integration with a Canadian model of practice. Canadian Journal of Occupational Therapy, 86(3), 220-231. https://doi.org/ $\underline{10.1177 / 0008417419832284}$

First Nations Information Governance Centre. (2014). Ownership, Control, Access and Possession $\left(O C A P^{r x}\right)$ : The path to First Nations information governance. https://fnigc.ca/wp- 
content/uploads/2020/09/5776c4ee9387f966e6771aa93a04f389 ocap_path to fn_informat ion governance en final.pdf

Fisher-Owens, S. A., Soobader, M. J., Gansky, S. A., Isong, I. A., Weintraub, J. A., Platt, L. J., \& Newacheck, P.W. (2016). Geography matters: State-level variation in children's oral health care access and oral health status. Public Health, 134, 54-63. https://doi.org/10.1016/ j.puhe.2015.04.024

Flicker, S., O'Campo, P., Monchalin, R., Thistle, J., Worthington, C., Masching, R., Guta, A., Pooyak, S., Whitebird, W., \& Thomas, C. (2015). Research done in "a good way": The importance of Indigenous Elder involvement in HIV community-based research. American Journal of Public Health, 105(6), 1149-1154. https://doi.org/10.2105/ajph.2014.302522

Frohlich, K. L., Ross, N., \& Richmond, C. (2006). Health disparities in Canada today: Some evidence and a theoretical framework. Health Policy, 79(2-3), 132-143. https://doi.org/10.1016/ j.healthpol.2005.12.010

Garces-Ozanne, A., Kalu, E. I., \& Audas, R. (2016). The effect of empowerment and self-determination on health outcomes. Health Education and Behavior, 43(6), 623-631. https://doi.org/10.1177/ $\underline{1090198116667665}$

Geldhof, G. J., Bowers, E. P., \& Lerner, R. M. (2013). Special section introduction: Thriving in context: Findings from the 4-H study of positive youth development. Journal of Youth and Adolescence, 42(1), 1-5. https://doi.org/10.1007/s10964-012-9855-7

George, J., MacLeod, M., Graham, K., Plain, S., Bernards, S., \& Wells, S. (2018). Use of traditional healing practices in two Ontario First Nations. Journal of Community Health, 43(2), 227-237. https://doi.org/10.1007/s10900-017-0409-5

Government of Canada. (2018). Non-Insured Health Benefits (NIHB) Medical Transportation Policy Framework (Interim). Indigenous Services. https://www.canada.ca/en/indigenous-servicescanada/services/first-nations-inuit-health/reports-publications/non-insured-healthbenefits/non-insured-health-benefits-nihb-medical-transportation-policy-framework-july-2005first-nations-inuit-health.html

Hampton, M., Baydala, A., Bourassa, C., McKay-McNabb, K., Placsko, C., Goodwill, K., McKenna, B., McNabb, P., \& Boekelder, R. (2010). Completing the circle: Elders speak about end-of-life care with Aboriginal families in Canada. Journal of Palliative Care, 26(1), 6-14. https://doi.org/ $\underline{10.1177 / 082585971002600103}$

Health Council of Canada. (2012). Empathy, dignity and respect: Creating cultural safety for Aboriginal people in urban health care. https://healthcouncilcanada.ca/files/Aboriginal_Report EN web final.pdf 
Ho, L. S., Gittelsohn, J., Harris, S. B., \& Ford, E. (2006). Development of an integrated diabetes prevention program with First Nations in Canada. Health Promotion International, 21(2), 8897. https://doi.org/10.1093/heapro/dak003

Horrill, T., McMillan, D. E., Schultz, A. S. H., \& Thompson, G. (2018). Understanding access to healthcare among Indigenous Peoples: A comparative analysis of biomedical and postcolonial perspectives. Nursing Inquiry, 25(3). https://doi.org/10.1111/nin.12237

Iseke, J. (2013). Indigenous storytelling as research. International Review of Qualitative Research, 6, 559-577. https://doi.org/10.1525/irqr.2013.6.4.559

Iwasaki, Y., \& Hopper, T. (2017). Leisure, engagement, and meaning-making among high-risk youth. Loisir et Société/Society and Leisure, 40(3), 324-339. https://doi.org/10.1080/ $\underline{07053436.2017 .1378504}$

Jordan's Principle Working Group. (2015). Without denial, delay, or disruption: Ensuring First Nations children's access to equitable services through Jordan's Principle. https://www.afn.ca/uploads/ files/jordans principle-report.pdf

Katz, A., Enns, J., \& Kinew, K. A. (2017). Canada needs a holistic First Nations health strategy. CMAJ: Canadian Medical Association Journal, 189(31), E1006-e1007. https://doi.org/10.1503/ cmaj.170261

Kyoon-Achan, G., Lavoie, J. G., Kinew, K., Phillips-Beck, W., Ibrahim, N., Sinclair, S., \& Katz, A. (2018). Innovating for transformation in First Nations health using community-based participatory research. Qualitative Health Research, 28(7), 1036-1049. https://doi.org/10.1177/ $\underline{1049732318756056}$

Kyoon-Achan, G., Lavoie, J. G., Kinew, K. A., Ibrahim, N., Sinclair, S., \& Katz, A. (2019). What changes would Manitoba First Nations like to see in the primary healthcare they receive? A qualitative investigation. Healthcare Policy, 15(2), 85-99. https://doi.org/10.12927/hcpol.2019.26069

Kyoon-Achan, G., Phillips-Beck, W., Lavoie, J. G., Eni, R., Sinclair, S., Kinew, K. A., Ibrahim, N., \& Katz, A. (2018). Looking back, moving forward: A culture-based framework to promote mental wellbeing in Manitoba First Nations communities. International Journal of Culture and Mental Health, 11(4). https://doi.org/10.1080/17542863.2018.1556714

Lans, C. (2016). Possible similarities between the folk medicine historically used by First Nations and American Indians in North America and the ethnoveterinary knowledge currently used in British Columbia, Canada. Journal of Ethnopharmacology, 192, 53-66. https://doi.org/ 10.1016/j.jep.2016.07.004

Lavoie, J. G. (2013). Policy silences: Why Canada needs a national First Nations, Inuit and Métis health policy. International Journal of Circumpolar Health, 72(1). https://doi.org/10.3402/ ijch.v72i0.22690 
Lavoie, J. G., Forget, E., Rowe, G., \& Dahl, M. (2008). Leaving for the city. Report of the Medical Relocation Project, Phase II. Centre for Aboriginal Health Research.

Lavoie, J. G., Forget, E. L., Prakash, T., Dahl, M., Martens, P., \& O'Neil, J. D. (2010). Have investments in on-reserve health services and initiatives promoting community control improved First Nations' health in Manitoba? Social Science and Medicine, 71(4), 717-724. https://doi.org/ 10.1016/j.socscimed.2010.04.037

Lux, M. K. (2010). Care for the 'racially careless': Indian hospitals in the Canadian West, 1920-1950s. Canadian Historical Review, 91(3), 407-434. https://doi.org/10.3138/chr.91.3.407

Miles, M., \& Huberman, A. M. (1994). Qualitative data analysis: An expanded sourcebook(2 $2^{\text {nd }}$ ed.). Sage Publications.

Minore, B., Boone, M., Katt, M., Kinch, P., Birch, S., \& Mushquash, C. (2005). The effects of nursing turnover on continuity of care in isolated First Nation communities. Canadian Journal of Nursing Research, 37(1), 86-100.

Murdoch-Flowers, J., Tremblay, M. C., Hovey, R., Delormier, T., Gray-Donald, K., Delaronde, E., \& Macaulay, A. C. (2019). Understanding how Indigenous culturally-based interventions can improve participants' health in Canada. Health Promotion International, 34(1), 154-165. https://doi.org/10.1093/heapro/dax059

National Inquiry into Murdered and Missing Indigenous Women and Girls. (2019). Reclaiming power and place: The final report of the National Inquiry into Missing and Murdered Indigenous Women and Girls. https://www.mmiwg-ffada.ca/final-report/

Oosterveer, T. M., \& Young, T. K. (2015). Primary health care accessibility challenges in remote Indigenous communities in Canada's North. International Journal of Circumpolar Health, 74(1). https://doi.org/10.3402/ijch.v74.29576

Pelletier, C., Dai, S., Roberts, K. C., Bienek, A., Onysko, J., \& Pelletier, L. (2012). Report summary. Diabetes in Canada: Facts and figures from a public health perspective. Chronic Diseases and Injuries in Canada, 33(1), 53-54. https://doi.org/10.24095/hpcdp.33.1.07

Phillips-Beck, W., Kyoon-Achan, G., Lavoie, J. G., Krueger, N., Kinew, K. A., Sinclair, S., Ibrahim, N., \& Katz, A. (2019). Negotiation, reciprocity and reality: The experience of collaboration in a community-based primary health care (CBPHC) program of research with eight Manitoba First Nations. The International Indigenous Policy Journal, 11(1). https://doi.org/10.18584/ iipj.2019.10.4.8334

Redvers, N., Marianayagam, J., \& Blondin, B. (2019). Improving access to Indigenous medicine for patients in hospital-based settings: A challenge for health systems in northern Canada.

International Journal of Circumpolar Health, 78(1). https://doi.org/10.1080/ $\underline{22423982.2019 .1577093}$ 
Richmond, C. A. M., \& Cook, C. (2016). Creating conditions for Canadian Aboriginal health equity: The promise of healthy public policy. Public Health Reviews, 37(2). https://doi.org/10.1186/ $\underline{\text { s40985-016-0016-5 }}$

Richmond, C. A. M., \& Ross, N. A. (2009). The determinants of First Nation and Inuit health: A critical population health approach. Health Place, 15(2), 403-411. https://doi.org/10.1016/ j.healthplace.2008.07.004

Royal Commission on Aboriginal Peoples. (1996). Gathering Strength (Vol. 3). http://data2.archives.ca/e/e448/e011188230-03.pdf

Smylie, J., \& Firestone, M. (2015). Back to the basics: Identifying and addressing underlying challenges in achieving high quality and relevant health statistics for Indigenous populations in Canada. Statistical Journal of the LAOS, 31(1), 67-87. https://doi.org/10.3233/sji-150864

Standing Committee on Indigenous and Northern Affairs. (2018). The challenges of delivering continuing care in First Nation communities. $42^{\text {nd }}$ Parliament, $1^{\text {st }}$ Session. https://www.ourcommons.ca/Content/Committee/421/INAN/ Reports/RP10260656/inanrp17/inanrp17-e.pdf

Suleiman, A. B., Soleimanpour, S., \& London, J. (2006). Youth action for health through youth-led research. Journal of Community Practice, 14(1-2), 125-145. https://doi.org/10.1300/ ¡125v14n01 08

Truth and Reconciliation Commission of Canada (TRC). (2015). Truth and Reconciliation Commission of Canada: Calls to Action. http://trc.ca/assets/pdf/Calls to Action English2.pdf

United Nations. (2008). United Nations Declaration on the Rights of Indigenous Peoples. https://www.un.org/development/desa/indigenouspeoples/wp-content/uploads/ sites/19/2018/11/UNDRIP_E_web.pdf

Ventura, J., \& Rueter, A. (2018, May 20). Indigenous health care workers use language to build trust and break down barriers. CBC News. https://www.cbc.ca/news/indigenous/indigenous-languagehealth-care-workers-1.4660009

Wakerman, J., Humphreys, J., Russell, D., Guthridge, S., Bourke, L., Dunbar, T., Zhao, Y., Ramjan, M., Murakami-Gold, L., \& Jones, M. P. (2019). Remote health workforce turnover and retention: What are the policy and practice priorities? Human Resources for Health, 17(1), 99. https://doi.org/10.1186/s12960-019-0432-y

Webster, P. (2018). Language barriers restricting access to health care for Indigenous populations. CMAJ: Canadian Medical Association Journal, 190 (24), E754-e755. https://doi.org/ $\underline{10.1503 / \mathrm{cmaj} .109-5613}$ 
Zubek, E. M. (1994). Traditional Native healing. Alternative or adjunct to modern medicine? Canadian Family Physician, 40, 1923-1931. 